\title{
An analysis of the use of the web-accessibility validator
}

\author{
Łukasz Krawiec \\ Wrocław University of Economics \\ ul. Komandorska 118-120, 53-345 Wrocław, Poland \\ Email: lukasz.krawiec@ue.wroc.pl
}

\begin{abstract}
A very important aspect of websites nowadays is their accessibility. Thanks to modern, constantly evolving technologies, it is possible to create friendly services for each user, regardless of his state of health. Web sites accessibility may be considered in aspects of their functionality and readability. One of methods for exploring this issue is the use of validators, i.e. automated tests to check the syntax of the documents posted on the Internet. The purpose of this paper is to analyze of the use one of the selected tools. The structure is as follows. First part of the article explained the importance of the accessibility of the web sites and present the most important accessibility standard. Then there is briefly characterized proposal of validators evaluation criteria for studying web-accessibility and present a list of selected tools in this way. In the next step is presented the results of analyzes carried out using the most promising tool. Finally, there are conclusions from the study. The paper is a continuation of the study of the website validation [1].
\end{abstract}

\section{INTERPRETATION OF WEBPAGE ACCESSIBILITY VALIDATION RESULTS}

$\mathbf{J}_{\mathrm{v}}^{\mathrm{u}}$ UST as any other type of common good, the World Wide Web network, with its ubiquitous nature, multitude of functionalities, and a broad range of benefits it offers to the modern information society seems to require proper care and maintenance in support of its continued development. This responsibility lies largely in the hands of web designers and those involved in the administration of individual pages and sites as fundamental units of the entire virtual reality of the WWW system. It is therefore advisable for any designer to not only emphasise the high quality of the distributed content, but also its proper presentation and its adjustment to the technical standards of the profession.

Webpage is a term so commonly used in modern contexts that it needs no detailed definition. However, from this study's perspective, it may seem useful to approach it in contrast to the term 'website', although both terms are often perceived as synonymous. A webpage is a document formatted in a HTML standard, containing multimedia elements arranged in an orderly fashion, and links (hyperlinks) to other webpages or to specific sections of the document itself [2]. In contrast to the above, a website is a term used to represent entire sets of cross-linked documents [3].

The application of best standards and practices in web design may be seen as a warrant to the quality of content presentation, functionality, and integration with the entire WWW system. Professional benefits offered by this approach require proper execution of the most fundamental qualitative features of WWW presentation, such as: web visibility, web benefits, web usability, and web accessibility [4]. The latter parameter is of special significance since, regardless of the original intentions of the designer, the ultimate objective here is to ensure effective presentation of the content and efficient propagation of information to the largest possible audience. Hence, the most obvious line of approach is to make sure that both the content and the rage of functionalities offered on the website can easily be accessed by all users, regardless of any disabilities or other conditions that may impair the reception of WWW content [5].

Webpage is a type of computer interface, so its features should be analysed in the area of human-machine interactions also. In this context, webpage accessibility represents a sum of user interface (UI) qualities designed to provide functionalities to all users, regardless of their preferred platform or client software, or any disabilities or impairments that may affect standard reception of the content [5]. In other words, webpages should be designed in accordance with the established standards of presentation to make them accessible from various platforms (e.g. both stationary and mobile), software profiles (operating systems and browsers), and configurations (e.g. with or without additional accessories or pointing devices, compatibility with audio readers). This requires a great deal of informed preparation and creative prognostication of possible scenarios, both at website design phase, and during code implementation. The large amount and the complexity of elements to be taken into account in the task of designing a well-accessible website may prove quite challenging to even the most experienced web designers.

\section{STANDARDS OF WeB ACCESSIBILITY}

'Best practices' is a term of a fairly general character, particularly when used in the complex context of web accessibility. Luckily, designers have easy access to a number of formal repositories of such standards, such as those formulated by the World Wide Web Consortium (W3C) in cooperation with the Web Accessibility Initiative (WAI). From the viewpoint of website designers, the most important segment of the WAI guidelines is the Web Content Accessibility Guidelines (WCAG). This document represents the most fundamental and the most widely propagated global standard of web content accessibility [6]. In addition to the above, researchers and analysts use a number of other standards and guidelines, as dictated by the 
need to generalise the findings or to present them in a specific legal context at regional or national level. A good example of such a supplementary set is the US set of laws and regulations on accessibility provided in Section 508 of the Rehabilitation Act of 1973 [7]. Standard supplementation is a justifiable approach, since no existing standards can warrant complete and exhaustive solution to the problems at hand. However, the WCAG - due to its specificity and the expertise of the authoring organisation (W3C) - may be considered as a fundament and a starting point for analyses and validations of web content accessibility.

Table 1 presents the structure and the organisation of WCAG guidelines in its current 2.0 version. Here, the four main principles are used as basis for the arrangement of 10 guidelines, and each guideline is evaluated on the basis of testable success criteria, producing a total of 61 elements, grouped into three levels of conformance with the guidelines of web accessibility: A - the lowest, offering basic accessibility; AA - medium, representing adequate accessibility of web content; and AAA - the highest standard, which (for design reasons) may not readily be available to all sites. To satisfy a certain level of accessibility, the page under examination should meet the whole set of success criteria for this level and the level(s) below it. In other words, to meet the AA level standards, a page should meet all criteria required at level AA and A, while the AAA conformance level would require the satisfaction of standards in all three levels from A to AAA [8].

To help users translate the WCAG success criteria into specific design choices, the standard is supplemented by a number of clarification documents and supporting materials. 'Techniques for WCAG 2.0' - one of the most important supplementary documents in this context - is a repository of techniques, common design errors, technical descriptions, practical examples, source code solutions, and conformity tests [9]. The document is available at https://www.w3.org/TR/WCAG20-TECHS.

TABLE 1.

THE STRUCTURE OF WCAG 2.0

\begin{tabular}{|l|l|lc|}
\hline \multicolumn{3}{|c|}{ WCAG 2.0 structure } \\
\hline Principles & Guidelines & Level A & $\begin{array}{c}\text { Success criteria } \\
\text { Level AA Level AAA }\end{array}$ \\
\hline
\end{tabular}

\begin{tabular}{|l|l|l|l|l|}
\hline 1. Perceivable & 1.1. Text alternatives & 1.1 .1 & \multicolumn{3}{|c|}{} \\
\cline { 3 - 5 } & 1.2. Time-based media & $1.2 .1-1.2 .3$ & $1.2 .4-1.2 .5$ & $1.2 .6-1.2 .9$ \\
\cline { 3 - 5 } & 1.3. Adaptable & $1.3 .1-1.3 .3$ & \multicolumn{3}{|c|}{} \\
\cline { 3 - 5 } & 1.4. Distinguishable & $1.4 .1-1.4 .2$ & $1.4 .3-1.4 .5$ & $1.4 .6-1.4 .9$ \\
\hline
\end{tabular}

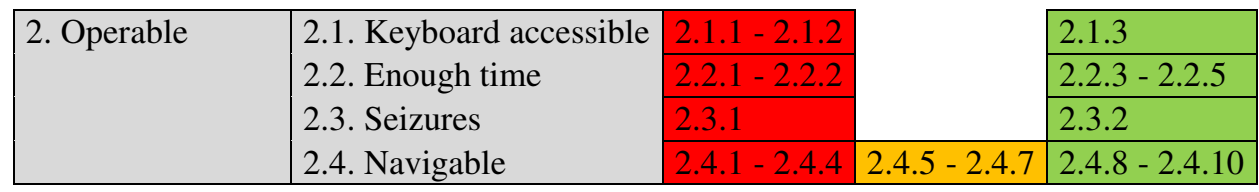

\begin{tabular}{|l|l|l|l|l|}
\hline 3. Understandable & 3.1. Readable & 3.1 .1 & 3.1 .2 & $3.1 .3-3.1 .6$ \\
\cline { 2 - 5 } & 3.2. Predictable & $3.2 .1-3.2 .2$ & $3.2 .3-3.2 .4$ & 3.2 .5 \\
\cline { 2 - 5 } & 3.3. Input assistance & $3.3 .1-3.3 .2$ & $3.3 .3-3.3 .4$ & $3.3 .5-3.3 .6$ \\
\hline
\end{tabular}

\begin{tabular}{|l|l|l|}
\hline 4. Robust & 4.1. Compatible & 4.1.1 - 4.1.2 \\
\hline
\end{tabular}

Source: Michael Gaigg: Über UI/UX Design, Web Content Accessiblity Guidelines (WCAG) 2.0: Overview and Structure, http://www.michaelgaigg.com/blog/2008/12/19/web-content-accessiblity-guidelines-wcag-20-overview-and-structure

(25.01.2017) (see also: [1]).

\section{VALIDATORS AND THEIR USE IN WEB ACCESSIBILITY TESTS}

There are many approaches in the verification of webpage conformance with web accessibility guidelines. Since some of the methods, such as expert evaluation, source code analyses and panel group observations, may prove fairly laborious, it may be advisable to reach for automated procedures offered by validators. These are sets of tools and instruments designed to perform automated verifications of technical conformance with WWW standards of web design. Reports generated by validators are produced based on analyses, valuations and assessments of the various webpage elements in relation to the adopted standard of evaluation [10]. 
Automated validators of webpage accessibility come in many forms and utilise a multitude of methods. Some common elements can be found between them, but there are also fairly large discrepancies on many levels, some of them of key significance to the final result, depending on the objectives adopted for testing procedures. Oftentimes, the same web page may be found to generate a different number of errors when tested in different validators, even when they use the same sets of accessibility criteria. Thus, before deciding on the use of validators for accessibility testing, it may be advisable to select the most appropriate variant, since this type of instruments is generally used in the early stages of analytical examination and, as such, they may greatly affect the course of subsequent activities [10].

Validators of online services have become increasingly popular over the last few years. Choosing the right one is not, therefore, easy. Specific tools vary greatly, by form of access, by the number of web pages they can verify at a time, by their interface, etc. When analysing various tools for automated tests and the accessibility requirements for websites, I have distinguished the following criteria [10], which can be used to compare and grade validator programs:

1. Verification according to WCAG 2.0 standard. This standard was created by the World Wide Web Consortium, an organisation that aims to create standards in the virtual reality of the Internet. The history of $\mathrm{W} 3 \mathrm{C}$, its importance for the development of the Internet, and the fact that hundreds of companies, institutions and schools belong to it, it can be assumed that their WCAG standard is the most complex and precise. Therefore, conformity to WCAG 2.0 standard should be a requirement for validator programs. A tool that can verify a website according to this standard should be preferred.

2. Verification according to other standards and additional test options. Validator programs are very useful in all tests of websites and in evaluating the quality of a website - company's website, for instance. In both these cases, any additional remarks can be very useful. A tool that allows testing according to other standards than the WCAG (such as the US Section 508), or testing for other criteria (such as spelling errors) should be preferred.

3. Number of web pages tested at a time. Free validator tools often test only one page at a time, while in most cases, the user wants to grade their whole website, not just a part of it. A tool that can verify several pages simultaneously should be preferred.

4. Way of presenting results. Accessibility evaluation is a complex subject and cannot be simplified into one final grade. A tool that generates an in-depth, precise and clear report of its analysis should be preferred.

5. Access form. This describes the way of using the automated tests: locally or online. Online access allows to test anywhere (anywhere with an Internet access, that is). A tool that offers both these forms of access should be preferred.

6. User interface. A graphical interface makes use easier, while a text interface (from the console, for instance) allows for better effectiveness or automatisation. Interface quality should also be taken into account. A tool offering a clear graphical interface with additional option of command console access should be preferred.

7. Software updates. These allow for stable program use, and when choosing a validator, one should check whether it is being updated, as well as whether or not it underwent a testing phase, or how long is it present on the market. A tool that is being supported, developed and suited to current standards should be preferred.

8. Cost. There are three main groups of validator software: commercial products, open source for non-commercial use, and open source. From the point of view of financial advantage only, free open source tool should be preferred.

Based on these criteria and prior research [5], the author produced a list of the most functional and practical instruments of this type:

- Cynthia Says - http://cynthiasays.com (10.02.2017),

- Functional Accessibility Evaluator https://fae.disability.illinois.edu (10.02.2017),

- Wave - http://wave.webaim.org (10.02.2017),

- HTML Validator - http://validator.w3.org (10.02.2017),

- $\quad$ aChecker - http://achecker.ca (10.02.2017),

- Utilitia - https://validator.utilitia.pl (10.02.2017),

- $\quad$ TAW Web Accessibility Test http://www.tawdis.net. (10.02.2017).

Each of the above validators uses the WCAG 2.0 standard as the main platform of reference. Regardless of the above, and due to the aforementioned discrepancies, results produced by those agents can differ to a large extent. Due to its features and comprehensive operation, the first tool - Cynthia Says was selected for further analysis.

\section{ANALYSIS OF THE VALIDATION PROCESS}

Accessibility analysis was submitted to the nonpublic (under construction) website, which is a virtual showcase of the small company, consisting of 6 subpages (Pages 1-6: Start, Company, Offer A, Offer B, Projects, Contact).

Results of validation processes are presented in four tables. Tab. 2 presents detailed results for a single WCAG 2.0 criterion within the main page of the website (Page 1). For each of the 61 success criteria, the following results may be obtained:

- Violation, representing lack of conformance with the required standard, 
- Warning, representing a potential violation of the standard, and requiring manual validation (designer or coder),

- Passed, representing the only positive outcome of the validation process,

- N/A - this result is returned when no elements in the code are found to correspond with the criterion under study; rows containing empty criteria are deleted.

Each of the above results is described by three elements:

- The WCAG technique, with code reference (e.g. H37) as a link to the detailed description of the problem provided in 'Techniques for WCAG 2.0' (see section 2 above for address),

- Meaning,

- Element - the corresponding part of content or code.

Using the formula provided at the bottom of Tab. 2, scores are calculated in the range of 0 to 100 for each subsequent criterion. The score represents the ratio of results in the 'passed' category to the total number of results generated.

Tab. 3 presents an overview of all success criteria generated for Page 1. Detailed descriptions of validation results were truncated and simplified to make them fit in a single row. Initial figures represent the number of occurrences in a given category, and codes in parentheses are references to specific sections of the 'Techniques for WCAG 2.0' document, to help users find detailed information on the problem and respond to it in an effective manner. The last column presents scores calculated for each of the studied criteria. Scores are also calculated for each WCAG level. Due to the characteristics of the A - AA AAA progression, these are presented in the form of cumulative sums (the last three rows of Tab. 3).

The above tables serve to illustrate and explain the approach in the calculation of validation scores based on the example of Page 1 content. Due to editorial constraints, the large volume of results obtained for the remaining pages of the website are presented in a collated form in Tab. 4. Since the results were found to be similar across the entire website, the final results for the site under examination were presented as average, and in separation into all three levels of the WCAG 2.0 compliance.

In summary, Tab. 4 (all scores summaries for the whole website) is a generalization of Tab. 3 (all scores for the first page only), which in turn is a generalization of Tab. 2 (descriptions for first exemplary guideline). To better illustrate the connections between them, Figure 1 was prepared.

Apart from the report of accessibility tests representing the site's compliance with the WCAG guidelines, the paper presents all violations registered in the process, i.e. all of the errors, omissions and other problems that seriously affect the website accessibility. Those errors are typically replicated across many pages, making them suitable for grouping into categories in Tab. 5.

TABLE 2.

DETAILED DESCRIPTION OF VALIDATION PROCEDURES FOR THE FIRST CRITERION, AS APPLIED TO PAGE 1

\begin{tabular}{|c|c|c|}
\hline \multicolumn{3}{|c|}{ WCAG 2.0 checklist - Page 1 - Guideline 1.1 .1 score (example of success criteria with description) } \\
\hline Violations & Warnings & Passed \\
\hline $\begin{array}{l}\text { Technique: H37: Using alt attributes on } \\
\text { img elements } \\
\text { Meaning: IMG element contains no ALT } \\
\text { attribute } \\
\text { Element: Line 476, column 6,img } \\
\text { element, SRC = } \\
\text { "http://i.imgur.com/xdyD1J2.png?1" }\end{array}$ & $\begin{array}{l}\text { Technique: F3: Failure of Success Criterion } \\
\text { 1.1.1 due to using CSS to include images } \\
\text { that convey important information) } \\
\text { Meaning: Ensure that image used in } \\
\text { background-url for element is not conveying } \\
\text { information } \\
\text { Element: Line 398, 407, 416, column } 6 \text {, } \\
\text { DIV elements } \\
\text { Technique: G144: Ensuring that the Web } \\
\text { Page contains another CAPTCHA serving } \\
\text { the same purpose using a different modality } \\
\text { Meaning: CAPTCHA found, please verify } \\
\text { that the information is conveyed through } \\
\text { audio as well as visual } \\
\text { Element: Line 520, } 521 \text { (...) column 9, } \\
\text { \#document element, \#content = "captcha" }\end{array}$ & $\begin{array}{l}\text { Technique: F30: Failure of } \\
\text { Success Criterion } 1.1 .1 \text { and } 1.2 .1 \\
\text { due to using text alternatives that } \\
\text { are not alternatives (e.g., } \\
\text { filenames or placeholder text) } \\
\text { Meaning: Image has descriptive } \\
\text { alt text }\end{array}$ \\
\hline \multicolumn{3}{|c|}{ Issues count } \\
\hline 1 & 2 & 2 \\
\hline
\end{tabular}


Score of 1.1.1 (percent passed) $=$ Passed / ( Violations

+ Warnings + Passed $) * 100=2 /(1+2+2) * 100=40$

Source: own research based on results obtained using Cynthia Says validator (see also: [1]).

TABLE 3.

DETAILED SUMMARY OF VALIDATION RESULTS FOR ALL CRITERIA, AS APPLIED TO PAGE 1

\begin{tabular}{|c|c|c|c|c|c|}
\hline & \multicolumn{5}{|c|}{ WCAG 2.0 checklist - Page 1 - Summary (extended example) } \\
\hline & \multirow{2}{*}{$\begin{array}{c}\text { Guide- } \\
\text { lines }\end{array}$} & \multicolumn{3}{|c|}{ Success criteria } & \multirow[b]{2}{*}{ Score } \\
\hline & & Violations & Warnings & Passed & \\
\hline & \multicolumn{5}{|c|}{ Level A } \\
\hline \multirow{39}{*}{ Table $2>>$} & 1.1 .1 & $1(\mathrm{H} 37)$ & $2(\mathrm{~F} 3, \mathrm{G} 144)$ & $2(\mathrm{~F} 30, \mathrm{H} 2)$ & 40 \\
\hline & 1.3 .1 & 0 & 0 & 2 (H42, H97) & 100 \\
\hline & 1.3 .3 & 0 & $1(\mathrm{~F} 14)$ & 0 & 0 \\
\hline & 1.4 .1 & 0 & $1(\mathrm{G} 14)$ & 0 & 0 \\
\hline & 2.1 .1 & 0 & 0 & 1 (SCR2) & 100 \\
\hline & 2.2 .1 & 0 & 1 (SCR1) & 0 & 0 \\
\hline & 2.3 .1 & 0 & 1 (G19) & 0 & 0 \\
\hline & 2.4 .2 & 0 & 0 & $1(\mathrm{H} 25)$ & 100 \\
\hline & 2.4 .3 & 0 & $1(\mathrm{H} 4)$ & 0 & 0 \\
\hline & 2.4 .4 & $1(\mathrm{H} 30)$ & 0 & 0 & 0 \\
\hline & 3.1 .1 & 1 (H57) & 0 & 0 & 0 \\
\hline & 4.1 .1 & 0 & $1(\mathrm{G} 134)$ & 0 & 0 \\
\hline & \multicolumn{5}{|c|}{ Level AA } \\
\hline & 1.4 .3 & $1(\mathrm{~F} 24)$ & $2(\mathrm{G} 145, \mathrm{G} 18)$ & 0 & 0 \\
\hline & 1.4 .4 & $1(\mathrm{C} 12)$ & $1(\mathrm{C} 17)$ & 0 & 0 \\
\hline & 1.4 .5 & 0 & 2 (C30, HS2) & 0 & 0 \\
\hline & 2.4 .6 & 0 & $1(\mathrm{G} 130)$ & 0 & 0 \\
\hline & 2.4 .7 & 0 & 1 (G149) & 0 & 0 \\
\hline & 3.1 .2 & 0 & 1 (H58) & 0 & 0 \\
\hline & 3.2 .3 & 0 & 1 (F66) & 0 & 0 \\
\hline & 3.2 .4 & 0 & 1 (G197) & 0 & 0 \\
\hline & \multicolumn{5}{|c|}{ Level AAA } \\
\hline & 1.4 .6 & $1(\mathrm{~F} 24)$ & $3(\mathrm{G} 145, \mathrm{G} 17, \mathrm{G} 18)$ & 0 & 0 \\
\hline & 1.4 .8 & $1(\mathrm{~F} 24)$ & $1(\mathrm{C} 17)$ & 0 & 0 \\
\hline & 3.2 .5 & 1 (H83) & 1 (SCR24) & 0 & 0 \\
\hline & 3.3 .5 & $1(\mathrm{G} 71)$ & 0 & 0 & 0 \\
\hline & 1.4 .9 & 0 & 1 (C30) & 0 & 0 \\
\hline & 2.1 .3 & 0 & 1 (HS5) & 0 & 0 \\
\hline & 2.2 .3 & 0 & 1 (G5) & 0 & 0 \\
\hline & 2.2 .4 & 0 & 1 (G75) & 0 & 0 \\
\hline & 2.3 .2 & 0 & 1 (G19) & 0 & 0 \\
\hline & 3.1 .3 & 0 & 1 (H60) & 0 & 0 \\
\hline & 3.1 .4 & 0 & $1(\mathrm{H} 60)$ & 0 & 0 \\
\hline & 3.1 .5 & 0 & 1 (G79) & 0 & 0 \\
\hline & 2.4 .9 & 0 & 0 & $1(\mathrm{H} 2)$ & 100 \\
\hline & 2.4 .10 & 0 & 0 & 1 (G141) & 100 \\
\hline & Sum A & 3 & 8 & 6 & 35,3 \\
\hline & Sum AA & 5 & 18 & 6 & 20,7 \\
\hline & Sum AAA & 9 & 31 & 8 & 16,7 \\
\hline
\end{tabular}

Source: own research based on results obtained using Cynthia Says validator (see also: [1]). 
TABLE 4.

SUMMARY OF VALIDATION RESULTS FOR ALL PAGES (PAGES 1-6) OF TESTED WEBSITE

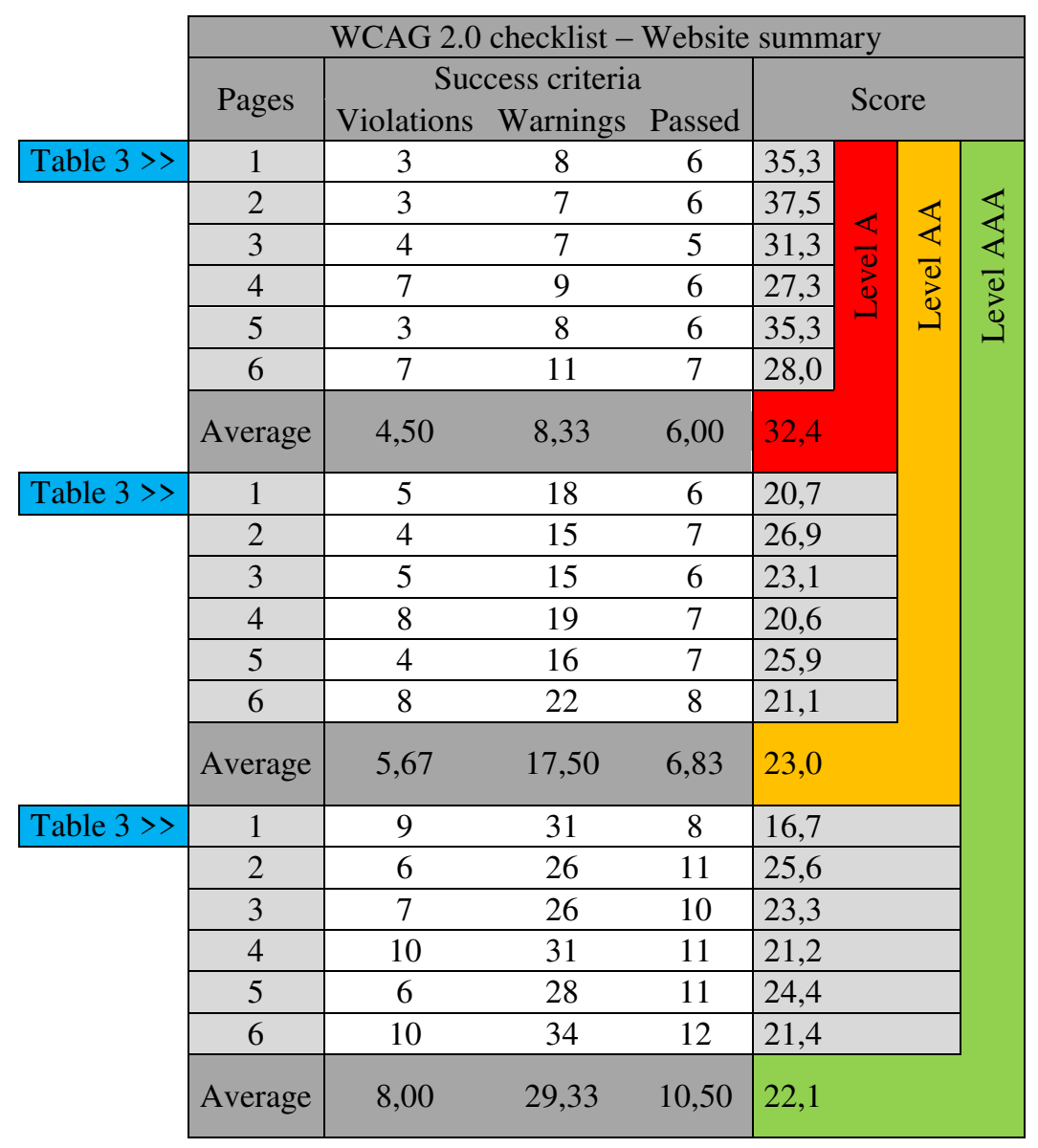

Source: own research based on results obtained using Cynthia Says validator (see also: [1]).

TABLE 5.

DETAILED REVIEW OF VIOLATIONS OF THE WCAG 2.0 STANDARD, AS REGISTERED AT THE TESTED WEBSITE

\begin{tabular}{|c|c|c|}
\hline & & WCAG 2.0 checklist - All pages - Violations (full description) \\
\hline & & $\mathrm{G}=$ Guideline, $\mathrm{T}=$ Technique, $\mathrm{M}=$ Meaning, $\mathrm{E}=$ Element \\
\hline & & Level A \\
\hline 1 & G & 1.1.1 [Non-text Content] \\
\hline & $\mathrm{T}$ & H37 Use alt attributes on img elements \\
\hline & M & IMG element contains no ALT attribute \\
\hline & $\mathrm{E}$ & All pages: img element, SRC = "http://i.imgur.com/xdyD1J2.png?1" \\
\hline & & Page 5: line 135, column 7, img element, SRC = "http://i.imgur.com/X8TwNrx.jpg" \\
\hline 2 & G & $2.4 .4[$ Link Purpose (In Context)] \\
\hline & $\mathrm{T}$ & H30 Providing link text that describes the purpose of a link for anchor elements \\
\hline & M & Anchor element does not have alternative text which describes purpose of the link \\
\hline & $\mathrm{E}$ & Page 1: a elements, $\mathrm{HREF}=$ =..." (news pages links \& social media links) \\
\hline & & Pages 2-6: a elements, HREF = "..." (social media links) \\
\hline 3 & G & 3.1.1 [Language of Page] \\
\hline & $\mathrm{T}$ & H57 Use language attributes on the html element \\
\hline & M & Page must specify LANG and/or XML:LANG attribute on the html element. \\
\hline & $\mathrm{E}$ & All pages: general \\
\hline 4 & G & 1.1.1 [Non-text Content] \\
\hline
\end{tabular}




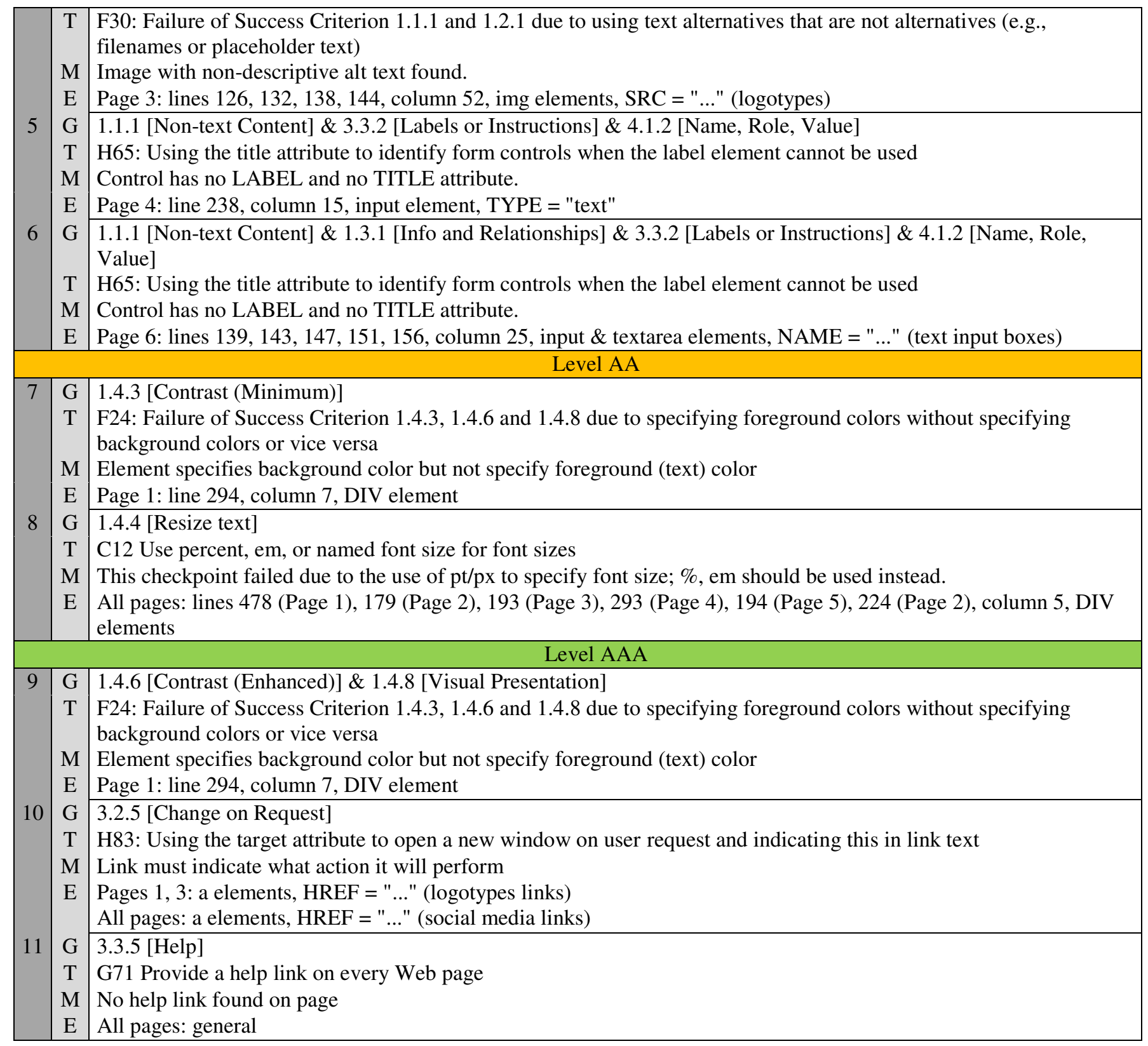

Source: own research based on results obtained generated by Cynthia Says validator (see also: [1]). 


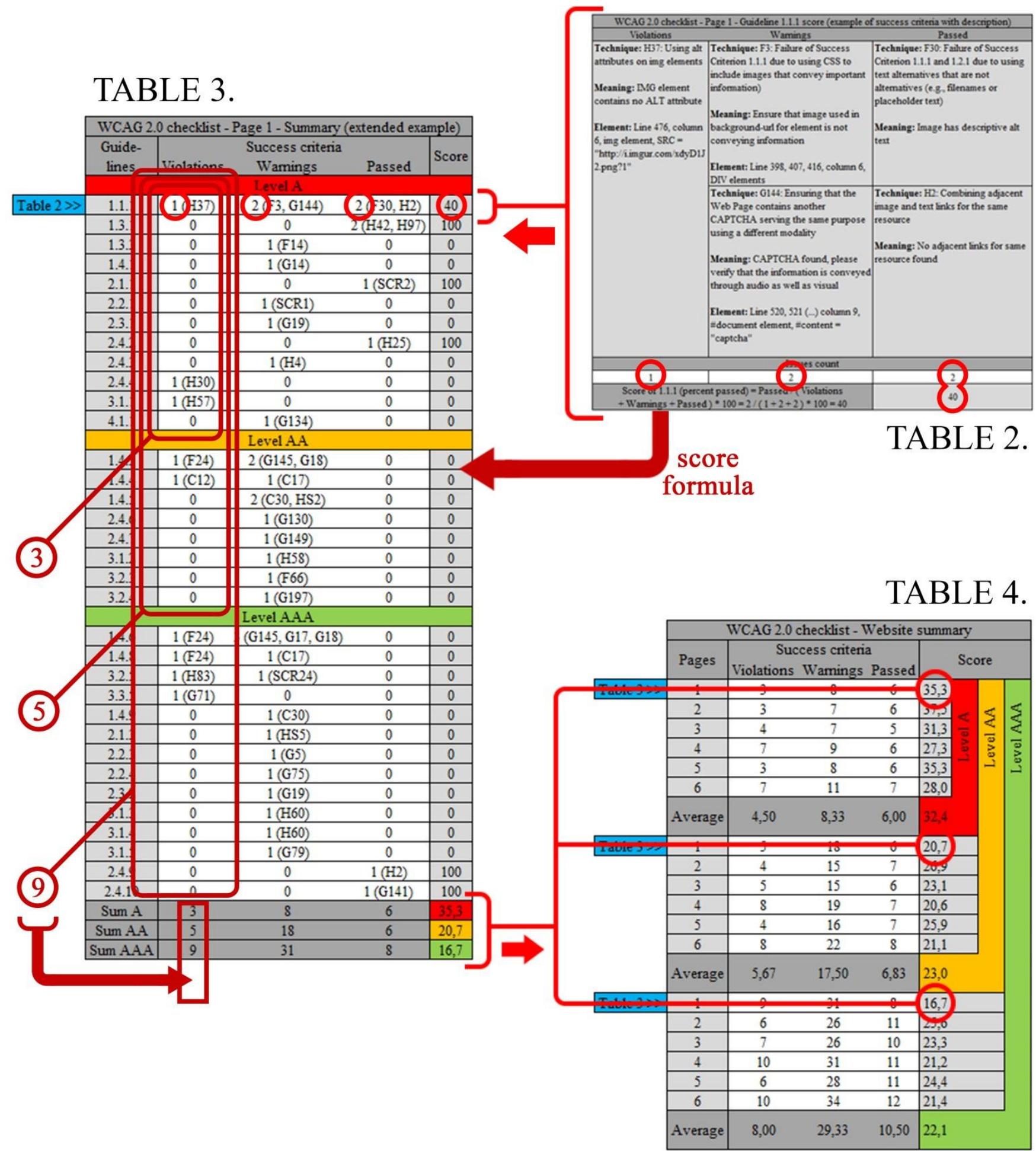

Fig. 1 Information flow between Tables 2-4

Source: own research. 


\section{RECAPITULATION AND CONCLUSIONS}

Web accessibility validation of the analyzed website was conducted in accordance with the WCAG 2.0 standard, for all three levels of compliance. The final report, consisting of numerical scores and detailed error reports, was generated on the basis of results produced by the Cynthia Says validator. Generated reports are fairly large, with most items presented in a nestled format to render the consecutive levels of detail in their presentation. Each item can also be opened in a new window. Due to editorial constraints and largely technical character of the results, this paper presents only a selection of those, to serve as examples in Tabs. 2. and 3.

Evaluating the effects of validation processes, one should bear in mind that the tested website is still under construction. The R\&D phase of the design is also a good time to conduct accessibility evaluations and to address any errors and violations of the WCAG 2.0 standard; for the website under examination, these are detailed in Tab. 5. Based on results presented in Tab. 4, the final score for the analyzed website is very low. Regardless of the adopted level of compliance, the overall ratio of 'passed' occurrences to all occurrences registered under the WCAG 2.0 success criteria for the site is very low, falling short of $40 \%$. Let us reiterate here: for a site to be judged as compliant at the very level of A, it must infallibly reach the $100 \%$ ratio within this level.

However, one can suggest at least two factors to justify such low scores obtained for the site under study. Firstly, for each of the three WCAG 2.0 compliance levels, the sum of warnings was found to be in excess of both the number of violations and 'passed' scores. Warnings represent elements which cannot be validated using the automatic methods; hence, they may not necessarily refer to errors in the website design but rather those of the tool itself. Such a dilemma can only be solved by the designer. However, the process is time-consuming and requires good knowledge of the site's source code. It is possible that the final score for the site under study would be much more favourable were we to apply this type of analytical reasoning. Secondly, it seems that the very notion of web accessibility is still lacking adequate propagation. If web designers fail to perceive web accessibility as the fundamental objective of their designs, there is small chance for it to satisfy the required standards to even a minimal extent, even when the quality of coding is otherwise flawless.

Cynthia Says is a well-designed tool with a convenient and intuitive interface. Most importantly, it provides useful and complex reports. But unfortunately they are not fully complete. The second problem is the items that the validator could not check automatically.

Previous research has shown that Cynthia Says is one of the best free license walidators, but also that none of them is perfect. Other tools were also used during the tests. For example, results were found to be largely similar to those produced by the Functional Accessibility Evaluator. One the other hand, additional or supplementary information could be obtained from other validators, such as Wave, HTML Validator, and aChecker. Rudimentary Web Developer Tools, of the type provided with most of the modern browsers for source code examination purposes, would be also very useful in the process. Therefore, prior to the initiation of testing procedures, and depending on webpage construction and reporting standard preferences, it may be advisable to utilise at least three mutually supplementing instruments.

\section{REFERENCES}

[1] Krawiec Ł., Nycz M., Pólkowski Z., Validation of website accessibility, a case study of DIMBI project, IEEE Xplore Digital Library, ECAI-2017 VOLUMES, Vol. 9-2017, ISSN-1843-2115, IN PRINT.

[2] Benicewicz-Miazga A., e-Business w Internecie i multimediach, Wydawnictwo Mikom, Warsaw, Poland, 2003, p. 24.

[3] Ziemba E., Metodologia budowy serwisów internetowych dla zastosowań gospodarczych, Wydawnictwo Akademii Ekonomicznej w Katowicach, Katowice, Poland, 2005, p. 27.

[4] Zawiła-Niedźwiecki J., Rostek K., Gąsiorkiewicz A. (red.), Informatyka gospodarcza, C. H. BECK, Warsaw, Poland, 2010, p. 227.

[5] Dudycz H., Krawiec Ł., The approach to the assessment of validators for studying web-accessibility - Orłowski A., Łukasiewicz P., Ząbkowski T., Gaj K., Szczesny W. (red.), Information Systems in Management, SGGW w Warszawie, Warsaw, Poland, 2017, IN PRINT.

[6] World Wide Web Consortium, Getting Started with Web Accessibility, https://www.w3.org/WAI/gettingstarted (20.01.2017).

[7] PowerMapper Website Testing and Site Mapping Tools, Government accessibility standards and WCAG 2, https:/www.powermapper.com/blog/governmentaccessibility-standards (20.01.2017).

[8] World Wide Web Consortium, Web Content Accessibility Guidelines (WCAG) 2.0, https://www.w3.org/TR/WCAG20 (25.01.2017).

[9] World Wide Web Consortium, Introduction to Techniques for WCAG 2.0, https://www.w3.org/TR/WCAG20-TECHS/intro.html (25.01.2017).

[10] Dudycz H., Krawiec Ł., Kryteria oceny walidatorów do badania dostępności stron WWW - Brzozowska A., Pawełoszek I., Turek T. (red.), Wiedza i technologie informacyjne $\mathrm{w}$ zarządzaniu procesami biznesowymi, Wydawnictwo Wydziału Zarządzania Politechniki Częstochowskiej, Częstochowa, Poland, 2016, p. 117. 